\section{Concentrating the mind}

SIR - Your News story (Nature 382, 657; 1996) about the ethical propriety of allowing a man about to be executed (Joseph Paul Jernigan) to donate his body to science (whence it was meticulously sectioned and recorded) provided a discourse worthy of mediaeval scholastics.

The Center for Bioethics thought there was a "possibility of coercion". How do you threaten a condemned man? With eternal damnation?

The lawyer thought it a bad example future prisoners might find the idea so attractive that they would neglect to appeal. I have known many dedicated scientists, but never any that committed.

Marcelle LaFollette thought that, had Jernigan known, he might have objected to being broadcast on the Internet. How many of us will come that close to immortality?

The Legal Defense Fund thinks it a bad precedent because future donations might be abused by "prison officials". How? Kept in the fridge? Black-market organ sales?

And, finally, the same fund objects that the informed consent was tainted: "you're hardly in the frame of mind to make some sort of long-term judgement" when on death row. But, if not when facing eternity, when?

A pity you didn't consult Dr Samuel Johnson, who wrote: "When a man knows he is to die in a fortnight, it concentrates his mind wonderfully."

\section{Stuart Martin}

Mt Mansfield Television Inc. WCAX-TV,

PO Box 608

Burlington, Vermont 05402, USA

SIR - I wish to support those who accept as ethical the 'visible man' and 'visible woman' anatomical displays on the Internet.

I do not support capital punishment. But I respect scientific ideals and ethics. I hereby freely declare that, if I were put on Death Row and executed, or killed in any other way, I would passionately wish my body to be used for any reputable scientific purpose. 'Reputable' includes respect for the principle that scientific knowledge is public knowledge. I hereby declare that I would be happy for my anatomy to be made available on the Internet.

A signed copy of this letter has been deposited with my personal solicitor.

\section{Michael Mclntyre}

Centre for Atmospheric Science,

Department of Applied Mathematics

and Theoretical Physics,

University of Cambridge,

Cambridge CB3 9EW, UK

e-mail: em@damtp.cam.ac.uk

http://www.damtp.cam.ac.uk/

atmos-dynamics
SIR - Although Meredith Wadman says of the 'Visible Human' that "the value of [this] anatomical database is undisputed", I would like to suggest that its worth has yet to be established. The fact that 600 institutions and individuals have licensed this database is hardly evidence of its worth. People download gigabytes of garbage from the Internet every day.

I am not saying that the 'Visual Human' is garbage. I just wonder what it has taught us that we didn't already know from the many beautifully detailed anatomical atlases and surgical texts produced over the past century.

\section{Richard Wassersug}

Department of Anatomy and Neurobiology,

Sir Charles Tupper Medical Building,

Dalhousie University,

Halifax, Nova Scotia B3H 4H7,

Canada

e-mail: tadpole@is.dal.ca

\section{Unscientific speculation}

SIR - David Swinbanks reported recently on the threat to public health in Japan caused by a massive outbreak of Escherichia coli 0157 enterocolitis in Sakai city, near Osaka (Nature 382, 567; 1996).

The health ministry named white radish sprouts as a likely source of the infection, but no evidence could be produced to support this hypothesis. Furthermore, the normal procedure in such circumstances of carrying out a case-control study, used recently, for example, to explain an outbreak of food poisoning through beef products in the United States, seems not to have been followed. Unscientific speculation and premature disclosure seem to put in doubt the reliability of the Japanese health ministry on such matters.

Yasuhara Tokuda

Okinawa Chubu Hospital,

Gushikawa City,

Okinawa, Japan

\section{Logical conclusion}

SIR - Edwards ${ }^{1}$ and later correspondents do not criticize Beck-Bornholdt and Dubben's interesting remarks ${ }^{2}$ about logic severely enough: the issue they discuss is central to the truth of quantitative statements. A British minister recently claimed, with the safety of eating beef in mind, that scientists mean something different by the word risk from what other people mean, rather than merely tending to quantify it more precisely.
Beck-Bornholdt and Dubben make two mistakes. The first is that the validity of syllogistic reasoning depends on the truth or certainty of the premises. A deductive argument is, as an argument, just as valid if it has false premises, let alone premises of low probability. Second, the inference about the Pope is simply a quantification mistake between 'any given human being' and 'any human being at all': more precisely, using the received conventions of elementary logic, between

$(\forall \mathrm{x})[\mathrm{HBx} \rightarrow\{P(\mathrm{x}=$ the Pope $)<1\}]$ which is true, and

$$
P[(\forall \mathrm{x})\{(\mathrm{x}=\text { the Pope }) \rightarrow \mathrm{HBx}\}]<1
$$

which is false.

So it seems the methods of statistical inference, and the Pope, can sleep easily in their beds.

John Godfrey

41 Lawford Road,

London NW5 2LG, UK

1. Edwards, A. W. F. Nature 382, 102 (1996).

2. Beck-Bornholdt, H. P. \& Dubben, H. H. Nature 381, 730 (1996).

- This correspondence is now closed - Editor, Nature.

\section{Storm in a teacup}

SIR - One of the many reasons I enjoy reading Nature is for the snippets of information about the 'classics' that come one's way: I learned, for example, of the source words in Greek for tectonics (382, 392; 1996), as also about the brilliant Michael Faraday's pioneering work on metal colloids (382, 581; 1996).

But I read with surprise the attribution to Caliban of the quotation "O brave new world that has such people in't" in Ryan Huxtable's review of The True History of Chocolate (382, 411; 1996). The Bard puts these words in Miranda's mouth in Act V, Scene i, of The Tempest.

Ajoy Baksi

Department of Geology and Geophysics, Louisiana State University,

Baton Rouge, Louisiana 70803, USA

\section{Train of thought}

SIR - Reading Philip Anderson's obituary of Nevill (no 'e') Mott (Nature 383, 121; 1996) reminded me of an anecdote I heard some 25 years ago.

Mott was travelling on the Paddington to Bristol train when three thoughts occurred to him. First, he was no longer at the physics department at Bristol but Cavendish Professor at Cambridge; second, he had travelled to London earlier that day by car; and third, he had been accompanied by his wife.

Michael Rodgers

Spektrum Academic Publishing,

33 Beaumont Street,

Oxford OX1 2PF, UK 